\title{
The prevalence of, and risk factors for, loneliness in later life: a survey of older people in Great Britain
}

\author{
CHRISTINA R. VICTOR*, SASHA J. SCAMBLER †, \\ ANN BOWLING** and JOHN BOND $\dagger \dagger$
}

\begin{abstract}
This study examines the prevalence of loneliness amongst older people in Great Britain, and makes comparisons with the findings of studies undertaken during the last five decades. In addition, the risk factors for loneliness are examined using a conceptual model of vulnerability and protective factors derived from a model of depression. Loneliness was measured using a self-rating scale, and measures of socio-demographic status and health/social resources were included. Interviews were undertaken with 999 people aged 65 or more years living in their own homes, and the sample was broadly representative of the population in $200 \mathrm{I}$. Among them the prevalence of 'severe loneliness' was seven per cent, indicating little change over five decades. Six independent vulnerability factors for loneliness were identified: marital status, increases in loneliness over the previous decade, increases in time alone over the previous decade; elevated mental morbidity; poor current health; and poorer health in old age than expected. Advanced age and possession of post-basic education were independently protective of loneliness. From this evidence we propose that there are three loneliness pathways in later life: continuation of a long-established attribute, late-onset loneliness, and decreasing loneliness. Confirmation of the different trajectories suggests that policies and interventions should reflect the variability of loneliness in later life, for undifferentiated responses may be neither appropriate nor effective.
\end{abstract}

KEY WORDS - loneliness, social exclusion.

\section{Introduction}

There is a consistent, strong and positive relationship between social engagement, social participation and 'quality of life' in old age (Bury and

* School of Health and Social Care, University of Reading, UK.

$\dagger$ University of Roehampton, London, UK.

** Department of Primary Care and Population Sciences, University College London, UK.

$\dagger \dagger$ Centre for Health Services Research, University of Newcastle-upon-Tyne, UK. 
Holme 1991). Surveys have consistently identified the importance of family and other relationships as central to the concept of quality of life and its enhancement (Bowling 1995), and social relationships and social engagement in later life are important factors in the model of successful ageing advanced by Rowe and Kahn (1997). It is then widely accepted that the social environment is a key influence upon the experience of later life and that, at the oldest ages, the social context and the physical environment exert a more potent influence upon the experience of old age than intrinsic genetic or biological factors.

The absence of social relationships, dissatisfaction with the extent or quality of such relationships, or low levels of social engagement and social participation, are likely to have a detrimental influence upon the quality of life of older people - raising which is a key objective of current British government policy. One state that has frequently been used as a marker of social exclusion is loneliness (Gibson 200I). The connections were examined several decades ago in several British studies (e.g. Sheldon 1948; Townsend I957; Tunstall I966) and in pioneering cross-national research (Shanas et al. I968). Recent initiatives designed to combat social exclusion have renewed interest in the influence of the 'social world' or social context upon the experience of ageing and later life. The 'first generation' empirical investigations of the nature and extent of social engagement amongst older people treated loneliness as the antithesis of social engagement and as an indication of 'dissatisfaction' with the extent and quality of social relationships. They aimed to measure the extent of loneliness and social isolation amongst older people, and to identify the risk factors for these states. They asked their respondents to rate their feelings of loneliness on Likert scales, from 'never' to 'always', with varying gradations of response (for detailed comparisons see Victor et al. 2002). The intention was the development of screening tools and interventions by which loneliness could be identified and social engagement promoted and enhanced.

\section{Perspectives on loneliness in later life}

A sense of loneliness is associated with an individual's evaluation of their overall level of social interaction, and describes a deficit between the actual and desired quality and quantity of social engagement. Three related but not identical concepts should be distinguished: 'being alone' (time spent alone), 'living alone' (simply a description of the household arrangements) and 'social isolation' (which refers to the level of integration with individuals and groups in the social environment). Whilst there is some commonality between these concepts, not all the overlaps are clear and the 
terms should not be used interchangeably (Townsend i968; Andersson ı998; De Jong Gierveld ı998; Victor et al. 2000; Holmen and Furukawa 2002).

At least four salient approaches and perspectives have been used in investigations of loneliness in later life: peer-group focus studies (crosssectional variations in the experience of loneliness in one cohort); agerelated studies (changes in loneliness in a cohort as it ages); generational contrasts (cross-sectional variations in loneliness among different age groups); and contrasting cohort studies (variations in the cross-sectional and longitudinal experience of loneliness in different cohorts and at different times). The focus of this paper is upon peer-group and age-related aspects of loneliness. We have previously reported both the quantitative and qualitative findings of a preliminary and local examination of cohortrelated changes in the prevalence of loneliness (Victor et al. 2001, 2002, 2004).

The examination of 'peer group' patterns of loneliness concentrates on the prevalence and distribution of 'loneliness' amongst older people (or other age groups) and seeks to identify 'vulnerable' or 'at risk' groups. Peer-group studies of loneliness predominate in previous research, especially that on older people, e.g. Wenger et al. (1996) in North Wales, Jones et al (1982) in South Wales, Holmen and colleagues (1992, I994) in Sweden, and De Jong Gierveld (1987) in Holland. In considering peergroup variability of loneliness among older people, both 'classic' risk factors have been identified and various models of causation suggested (see Wenger et al. 1996; De Jong Gierveld I998; Fees, Martin and Poon I999). Five sets of factors have been shown to be consistently associated with loneliness: socio-demographic attributes (living alone, being female, not having any surviving children, living arrangements, being aged 75 or more years); material circumstances (poverty, limited education and low income); health resources (disability, self-assessed health, mental health, cognitive function, anxiety and depression); social resources (size of social network, isolation, time alone and presence of a confident); and life events (recent bereavement and admission of a relative/spouse into care). For a comprehensive review, see De Jong-Gierveld (I998).

Many of these variables are strongly inter-related. Only a few authors have been able to undertake sophisticated statistical analysis to decompose the confounding influences and to identify the factors that are 'independently' associated with loneliness. With data from Gwynedd, North Wales, Wenger et al. (I996) developed a statistical model of loneliness using two outcome measures: 'self-assessed loneliness' and the 'aggregate loneliness index' (Wenger I983). Living alone, a restricted support network and poor self-assessed health were found to be independently associated 
with both measures. In addition, marital status, desire for more friends, and duration of relationship with a key confidante were significantly associated with the self-assessed measure; and ethnicity (as measured by being 'Welsh') was independently associated with the aggregate measure. This latter variable reflects the specificity of the study area and the limits to the generalisability of the findings, although it is clearly acting as a proxy for integration in a specific social context. Another local study, in North America by Fees, Martin and Poon (1999), reported that anxiety, low levels of telephone contact (but not direct contact) and higher age were associated with loneliness.

No recent British national study has been found that examines the predictors and risk factors for loneliness. Furthermore, previous published studies have succeeded only in identifying the factors that place older people at increased risk of loneliness, and there has been little attention to the factors that offer protection against loneliness in later life. Developing our knowledge of the protective factors is important because it may lead to more effective ameliorative interventions. We suggest that Brown and Harris's (1978) social model of depression helps in understanding and conceptualising the experience of loneliness in later life. They identified psychological, environmental and social risk factors for depression and, importantly for our approach, distinguished a set of background social factors (such as social class) that are associated with vulnerability to depression, from the factors that protect against depression. The Brown and Harris model is complex, and there are many inter-relationships between the two sets of factors. Moreover, the specific meaning of several of the identified factors for particular individuals will vary, but we believe that this disaggregated approach to the complex set of relationships has considerable potential.

The focus of 'age-related' studies is to compare and contrast the experience of loneliness in later life with that experienced at other phases of the lifecourse. This perspective suggests three distinct types of loneliness in later life: (a) as a continuation from earlier phases of life, (b) as a new experience, and (c) as a state that has reduced in intensity from earlier in life. These are conceptually and theoretically distinct and link both to Weiss's (I973) notions of 'temperamental' and 'situation' loneliness, and to Witzelben's (1968) ideas of 'primary' and 'secondary' loneliness. Primary or temperamental loneliness stems from the personality or mindset of the individual. In contrast, secondary or situational loneliness develops in response to changes in external circumstances or the socio-environmental context.

Longitudinal studies, as by Holmen and Furukawa (2002), Wenger and Burholt (2004) and Tijhuis et al. (1999), are a more robust method for 
identifying such distinctions than cross-sectional studies; and biographical and life-review studies as well as case studies (e.g. Seabrook i973) can also enhance our understanding of the dynamic of loneliness and social engagement. Such studies are however rare, and the prevailing perspective upon loneliness in later life remains sadly static. By distinguishing the different trajectories or pathways into the experience of loneliness in later life using biographical approaches, we may begin to develop and evaluate a more sophisticated repertoire of interventions to combat loneliness, and at the same time enhance our theoretical and conceptual understanding (Victor et al. 2004).

Using data from a project funded as part of the United Kingdom Economic and Social Research Council (ESRC) Growing Older programme, this paper examines patterns of peer-group and age-related loneliness in a representative contemporary British cohort of older people living in the community (those in long-term institutional care were excluded). The paper presents data on both the prevalence of loneliness among older people and in specific social categories, it identifies the statistically significant covariates, and it develops models of the factors that are associated with both vulnerability and protection. The paper therefore builds upon our previous reports, on the preliminary findings of the survey of loneliness in relation to loss (Victor et al. 200I), and on cohort variations in the prevalence of loneliness among those aged 6o-74 years (Victor et al. 2002). The presented statistical model of loneliness is the first to be developed in Britain using contemporary and nationally-representative data.

\section{Method}

\section{Study design}

The data presented in this paper derived from the Office for National Statistics (ONS) Omnibus Survey of households in Great Britain. This is a face-to-face interviewer-administered survey that is conducted monthly or bi-monthly, depending upon demand, with approximately 2,ooo people aged i 6 or more years. It randomly selects 30 addresses in each of roo randomly selected 'postal sectors', which provide a broadly representative sample of the adult population resident in the community. Researchers can purchase specific modules or questions on the survey, or use it to identify eligible research participants, as in this study. We asked Omnibus Survey respondents aged 65 or more years to participate in a second interview that focused on quality of life (see Bowling et al. 2002; Ayis, Gooberman-Hill and Ebrahim 2003). To control for seasonality and to obtain enough statistical power, all the older respondents to the April, 
September and November 2000 and the January 200 sweeps were invited for the second interview. ${ }^{1}$

\section{Measures}

The survey collects many and diverse variables, but for this paper 'loneliness' was of special interest and two approaches to its measurement were available: self-report measures and derivative scales or aggregate measures. The first use of a single question to elicit a self-rated and scaled measure of loneliness appears to have been by Sheldon (1948), but it has subsequently become customary in Britain (see Victor et al. 2002), in continental Europe (Holmen et al. 1992, 1994), and in Australia (Iredell et al. 2003). Self-report measures are simple to use, appear to be highly acceptable to research participants, and ask directly about feelings of loneliness - but their simplicity is also a weakness. The question presumes a common understanding of the concept of loneliness by a study's participants, when it is likely that the nature and meaning of the concept will diverge among different groups of older people and over time. Furthermore, loneliness may be seen or experienced as 'stigmatising' and as a state which compromises or damages a person's identity. Consequently, study participants may express a 'public' view and not admit to feelings of loneliness. Self-report measures may therefore capture only the publicly-declared prevalence of loneliness, which may differ from the privately-felt extent of the feeling.

The alternative approach to the measurement of loneliness has been to develop derivative measures, such as the University of California Los Angeles (UCLA) loneliness scale (Russell I996), and those devised by De Jong Gierveld (1987) and Wenger (1983). All three have undergone psychometric testing of their validity and reliability and have been used with older people (see Scharf et al. 2002). Nonetheless, all demonstrate cultural specificity and rely upon indirect questions about social engagement. They therefore make assumptions about the definition and meaning of loneliness and about the links between social engagement and loneliness. Although Holmen and Furukawa (2002) suggested that the selfreport measures are more appropriate than the UCLA scale, there is much scope for further research on the merits of the different approaches and measures.

The selection of topics and measures and the definition of the study population were influenced by two objectives, to investigate cohort changes in loneliness and to compare the findings with those of the 'classic' British studies (Victor et al. 200I). To replicate earlier work, a self-assessed loneliness rating on a four-point scale from 'always' to 'never' lonely was used. Age-related loneliness was measured using a question that invited 
T А в L E I. Resource variables that were significantly associated with loneliness

\begin{tabular}{|c|c|}
\hline Association & Variable lists \\
\hline Yes & $\begin{array}{l}\text { Age, sex, marital status, household status, tenure, car ownership, education, } \\
\text { social class, problems with sight, problems with hearing, chronic illness, } \\
\text { health rating, fall in previous year, Townsend disability score, expected health } \\
\text { in old age, GHQ score, time alone, increased time alone in previous decade, } \\
\text { increase in loneliness in previous decade, voted in last election, confident, and } \\
\text { activities in previous week. }\end{array}$ \\
\hline No & $\begin{array}{l}\text { Proximity of children, proximity of relatives, contact with neighbours, } \\
\text { contact with friends, direct and by phone, contact with family, direct and } \\
\text { by phone, and environmental factors. }\end{array}$ \\
\hline
\end{tabular}

Note: Statistical significance was identified at $p<0.05$. 'Yes' indicates that the association was significant.

respondents to compare their current level of loneliness with how they felt a decade earlier, and to rate the comparison as 'better', 'worse' or 'unchanged'. The question recorded changed expectations of loneliness across the lifecourse, and is therefore problematic, especially because of difficulties with response shift (Schwartz and Sprangers 2000). It did, however, provide an innovative and dynamic approach to the study of social participation in later life and enabled different pathways or trajectories into loneliness in later life to be described and to be compared with the qualitative data (Victor et al. 2004).

Most of the independent predictors of loneliness derived from previous studies, but the list was extended to incorporate factors (such as ethnicity) that had not previously been measured in British studies. There is insufficient space to detail each question, but the majority of variables included standard items from major national surveys such as the General Household Survey. The variables were organised into four broad resource categories which were hypothesised as being linked with the experience of loneliness in later life: socio-demographic, health, material and social resources (for the full list, see Table I).

\section{Analysis}

The preliminary analysis used chi-squared tests to evaluate the associations between loneliness and specific risk factors grouped into five categories (these matched the resource categories but distinguished social resources and the social network). Odds-ratios and 95 per cent confidence intervals were also calculated. All variables with an initial significant relationship with loneliness were entered into the model. Ordered logistic regression was used to test the independence of association with a categorical measure of loneliness ('always/often', 'sometimes' and 'never'): a contrast with the 
dichotomous measure ('lonely' or 'not lonely') used by Wenger et al. (1996). It was believed that the dichotomy was inadequate to capture the complex and differentiated feelings associated with the experience of loneliness, and that it was imperative not to force 'intermediate' states into an unqualified marker of either the presence or absence of loneliness.

\section{Results}

Study response rate and the characteristics of the samples

The Omnibus Survey sweeps contacted I,598 respondents aged 65 or more years, of whom 1,323 were eligible for inclusion in the module (i.e. the household had an older person who consented to be approached for the supplementary interview). At follow-up, 24 of these addresses were found to be ineligible, leaving a potential sample of $\mathrm{I}, 299$. Of this number, $243(\mathrm{r} 9 \%)$ declined to participate and $57(4 \%)$ were not contactable. This yielded an achieved sample of 999 respondents: a response rate of 77 per cent of those identified as eligible for the study and 63 per cent of those who participated in the index waves of the Omnibus Survey.

The characteristics of the sample broadly represented the general population of older people living in the community in Britain. Just over one-third $(37 \%)$ of the respondents lived alone, and 42 per cent were aged 75 or more years; both rates being identical to the national level (Walker et al. 2002). The sample had significantly more widows than the general population (39\% compared with $33 \%$ ). Because of the higher reported prevalence of loneliness amongst widowed persons, this over-representation may elevate this study's crude prevalence estimate. In terms of other resource factors, rates of chronic illness approximated to national norms for older people living in the community: 38 per cent did not report a chronic illness or disability ( $39 \%$ nationally), and 73 per cent rated their health as 'good' or 'very good' ( $7 \mathrm{r} \%$ nationally). The indirect indicators of material resources 'access to a car' and 'home ownership' were both two per cent higher than the national figures ( $56 \%$ and $68 \%$ respectively). Levels of social contact with friends, family and neighbours were high and reflected the national pattern. Both nationally and in our sample, twothirds of older people were in direct contact with their family at least weekly, whilst three-quarters saw friends weekly (Walker et al. 2002).

\section{Prevalence of loneliness}

The majority (6r \%) of the participants rated themselves as 'never' lonely, approximately one-third ( $3 \mathrm{I} \%)$ as 'sometimes' lonely, five per cent as 'often' lonely, and two per cent as 'always' lonely. Of the $385(38 \%)$ who 
reported any level of loneliness, 54 per cent stated that this was felt most acutely at specific times, especially during the evenings $(67 \%)$, weekends (30\%) and holidays $(7 \%)$.

\section{Peer-group patterns of loneliness}

The 'risk factors' for loneliness were grouped into four main domains: socio-demographic, material, health and social resources. The initial univariate analysis demonstrated a plethora of factors associated with loneliness (for a summary, see Table I). Indeed 26 individual variables demonstrated a statistically significant relationship with loneliness. For example, the oldest, the widowed and those living alone had relatively high rates of loneliness. ${ }^{2}$ Chronic health problems (long-standing limiting illness), disability, sight or hearing problems, reported depression or a high score on the General Health Questionnaire (GHQ), an internationally used measure of general psychiatric morbidity (Bowling 200I), measures of material resources including possession of financial assets (house tenure and car ownership), and educational qualifications also demonstrated statistically significant relationships with loneliness.

The relationship with social resources was more complex. Reported levels of contact with family or friends either directly or by telephone did not show any statistically significant association with reported levels of loneliness. Proximity or number of family or friends also failed to demonstrate a significant relationship with the reported experience of loneliness. There was, however, a significantly high rate of loneliness (I8\%) amongst those who were 'always' or 'often' alone. Among those who reported that they spent more time alone than a decade previously, i8 per cent were always/often lonely.

Clearly, many of the factors associated with loneliness in our initial analysis were inter-related. To evaluate the independence of the observed associations and to identify the factors that were statistically associated with loneliness, ordered logistic regression modelling was undertaken. Two models were used: Model I included all the variables identified as significant in the preliminary analysis; Model 2 excluded the variable that measured changes in loneliness during the previous decade. Both models identified two sets of factors: those associated with increased risk of loneliness, the vulnerability factors; and those that conferred a lower risk of reported loneliness, classified as protective (Table 2).

Model I identified six independent factors that put older people at a higher than average risk of reporting that they experienced loneliness and therefore indicated vulnerability. Of these, three described social resources and three health resources. The social resource measures were 
T A B L E 2. Factors independently associated with loneliness

\begin{tabular}{|c|c|c|c|c|c|c|c|c|}
\hline \multirow[b]{2}{*}{ Factors } & \multirow[b]{2}{*}{$\mathrm{N}$} & \multicolumn{3}{|c|}{ Percentage lonely } & \multicolumn{2}{|c|}{ Univariate analysis } & \multicolumn{2}{|c|}{ Multivariate analysis } \\
\hline & & $\begin{array}{c}\text { Always/ } \\
\text { often }\end{array}$ & $\begin{array}{c}\text { Some- } \\
\text { times }\end{array}$ & Never & $\begin{array}{l}\text { Unadjusted } \\
\text { odds-ratio }\end{array}$ & C.I. & $\begin{array}{l}\text { Adjusted } \\
\text { odds-ratio }\end{array}$ & C.I. \\
\hline \multicolumn{9}{|l|}{ Age group (years) } \\
\hline $65-74$ & $5^{82}$ & 6 & $3^{8}$ & 55 & I.OO & & I.OO & \\
\hline $75^{-84}$ & 343 & I3 & 38 & 49 & I. 40 & І.08-- .80 & 0.83 & o.6o-I.I4 \\
\hline $85+$ & 72 & I8* & 24 & $5^{8}$ & I.I2 & I.02-I.87 & $0.4 \mathrm{I}$ & $0.2 \mathrm{I}-0.78$ \\
\hline \multicolumn{9}{|c|}{ Educational qualifications } \\
\hline Yes & 344 & $4^{*}$ & 33 & 63 & 0.54 & $0.4^{2-0.70}$ & 0.72 & $0.5^{2-}-0.99$ \\
\hline No & 653 & I2 & 39 & 49 & I.OO & & I.OO & \\
\hline \multicolumn{9}{|l|}{ Marital status } \\
\hline Married & 460 & I & $2 \mathrm{I}$ & 78 & I.OO & & I.0O & \\
\hline Single & 79 & 9 & 45 & 46 & 4.IO & $2.5^{6-6.69}$ & I.50 & $0.8 \mathrm{I}-2.75$ \\
\hline Divorced & 72 & 8 & 46 & 46 & 4.00 & เ. $86-6.62$ & I.80 & $0.99-4.95$ \\
\hline Widowed & 386 & $20^{*}$ & 53 & 28 & 9.78 & $7.17^{-1} 3.2$ & $3 \cdot 30$ & $2.14-4.95$ \\
\hline \multicolumn{9}{|l|}{ Health rating } \\
\hline Good/v. good & 729 & 7 & 32 & $6 \mathrm{I}$ & I.00 & & I. .00 & \\
\hline Poor & 59 & $19^{*}$ & 34 & 47 & $2.5^{\mathrm{I}}$ & I. $35^{-4} 4.70$ & I.07 & $0.57^{-1.97}$ \\
\hline Fair & 206 & 9 & 33 & $5^{8}$ & I. 39 & $0.88-2.20$ & I.I4 & $0.5^{\mathrm{I}-2.53}$ \\
\hline \multicolumn{9}{|c|}{ Expected health in old age } \\
\hline Better & 298 & 7 & 36 & 57 & I. .00 & & I. .00 & \\
\hline Worse & 274 & $15^{*}$ & 39 & 46 & г. 62 & I.I7-2.23 & I.I 6 & o.8I-I.65 \\
\hline Same & $4 \mathrm{OI}$ & 8 & 36 & $5^{6}$ & I.03 & $1.17-2.23$ & I.05 & o. $67-1.63$ \\
\hline \multicolumn{9}{|c|}{ Loneliness compared with to years ago } \\
\hline Same & 605 & $2^{*}$ & 24 & 74 & I.00 & & I.00 & \\
\hline More & $3 \mathrm{OI}$ & 25 & 62 & I3 & 8.00 & $4.85-13.2$ & 3.78 & $2.18-6.49$ \\
\hline Less & 90 & 4 & 40 & $5^{6}$ & $0.4^{2}$ & $0.25^{-0.70}$ & $0.5^{\circ}$ & $0.3^{\mathrm{I}-0.82}$ \\
\hline \multicolumn{9}{|l|}{ Time alone } \\
\hline Always/often & $47 \mathrm{I}$ & $18^{*}$ & 49 & 33 & 9.87 & $5 \cdot 7-17.95$ & 3.22 & I. $68-6.23$ \\
\hline Seldom & 430 & 2 & 28 & $7 \mathrm{I}$ & $5 \cdot 37$ & $2 . \mathrm{II}-7.00$ & 2.12 & I. $46-3.00$ \\
\hline Never & $9^{6}$ & I & 20 & 79 & I.OO & & I. .00 & \\
\hline \multicolumn{9}{|l|}{ GHQ I2 score } \\
\hline None & 396 & 3 & 32 & 66 & I.00 & & I.00 & \\
\hline Moderate & 386 & 8 & 40 & $5^{2}$ & 0.49 & o. $19-0.8$ & I. 35 & $0.96-$ I.92 \\
\hline Severe & 215 & $25^{*}$ & $4 \mathrm{I}$ & 34 & I.4I & I.04-I.79 & 3.25 & $2.14-4.95$ \\
\hline
\end{tabular}

Notes: *Differences statistically significant at five per cent level using chi-squared test. C.I. 95 per cent confidence interval. For details of the measures, see text.

'marital status' (with all groups being more vulnerable than married people), 'time spent alone', and 'increases in loneliness over the previous decade'. The health resource measures were a 'high GHQ score', which is an indirect indicator of poor mental health; 'worse than expected health in later life' and 'poor current evaluation of health status'. Two factors appear protective, being independently associated with lower reported levels of loneliness: 'advanced age' and 'possession of post-basic educational qualifications'. The results of Model 2 replicated the findings 
with one exception, the protective effect of education was no longer significant.

\section{Age-related loneliness}

By inviting the respondents to compare their current level of loneliness with that of a decade earlier, the data were available to investigate agerelated patterns of loneliness. Approximately two-thirds (68\%) of the participants reported that their loneliness rating had not changed during the previous decade, for 23 per cent it had deteriorated, while io per cent were less lonely. The retrospective comparison threw light on the different 'trajectories' of loneliness through later life, and enabled those for whom loneliness was a new experience to be differentiated from those for whom it was a continuing state. Among the 973 respondents for whom this analysis could be undertaken, 54 per cent rated themselves as not lonely at both times, I5 per cent had been 'often/always lonely' at both times, Io per cent had become less lonely, and for 2I per cent the level of loneliness had increased.

\section{Discussion}

Loneliness is still conceptualised by many, including older people themselves, as a problem specific to old age, despite much evidence that other population groups have the experience (Ellaway, Wood and MacIntyre I999). Personal social capital is clearly an important element in quality of life, as Bowling et al. (2002) and Scharf and Smith (2004) have demonstrated. Although not a prime objective, this study has demonstrated that levels of social contact with family, friends and neighbours were high: twothirds of the respondents had direct weekly contacts with family and/or friends and 80 per cent telephone contacts.

Some limitations of the study qualify the inferences that may be drawn from the findings. The response rate was acceptable at 77 per cent, but there was an over-representation of the widowed. Nonetheless, the characteristics of the sample approximated to those of the older population of Britain as estimated from the 200I population census and the 200I General Household Survey (Walker et al. 2002). ${ }^{3}$ More specifically, the respondents had similar age and household status profiles as the general population. Morbidity levels were also similar but there was a significant over-representation of the widowed. ${ }^{4}$

The self-report measure of loneliness used in this study was similar to that frequently employed in Britain and North America. Its use facilitated the examination of cohort changes in loneliness between studies, although 
the exercise presumes a common understanding of the term 'loneliness' amongst respondents. Research with older people is rarely participative and their responses to interviewers may be 'publicly-acceptable' accounts and fail to report socially undesirable or stigmatising states such as loneliness (Cornwell i984). But neither are derived scales of loneliness immune from these problems, for many of the items on which they are built suffer from a similar selectivity of response. Furthermore, despite their demonstrated (if variable) psychometric robustness, such scales are problematic because of variations in the cultural and generational contexts in which they were developed and the lack of agreement as to the conceptual and theoretical basis of loneliness. Our choice of a self-report measure was based upon the requirement of comparability with the index studies.

\section{The prevalence of loneliness}

British community studies have reported rates of loneliness among those aged 65 or more years of from five to 16 per cent (Sheldon 1948; Townsend 1957, I968; Tunstall ı966; Hunt 1978; Bond and Carstairs I982; Qureshi and Walker I989). The median reported rate is approximately 9 to Io per cent (Victor et al. 2000). This study's estimate that seven per cent were 'often' or 'always' lonely is comparable, and supports our earlier finding that no substantial increase in the prevalence of severe loneliness has occurred during the last 60 years (Victor et al. 2002). This result is similar to those for London of Prince et al. (1997), for northern Europe by Holmen and Furukawa (2002), for North America (Townsend I968), for Australia (Iredell et al. 2003), and for Saudi Arabia (Abolfotouh et al. 200I), although differs from an estimate for southern Europe (Walker and Maltby 1997).

One can conclude that, despite the major changes in society in recent decades, the prevalence of 'severe' loneliness has been remarkably stable. On the other hand, almost one-third of the participants in this study reported that they were 'sometimes lonely', a much larger proportion than the II-22 per cent reported in the earlier British research (Sheldon I948; Townsend I957; Tunstall ı966; Weeks i994). Given the apparent increase in 'intermediate loneliness', the percentages reporting that they were 'never lonely' decreased over time. It is not clear if the shift in pattern represents changes in the experiences of older people, variations in expectations concerning the nature of later life between cohorts, or a changed willingness of interview respondents to 'admit' to a non-severe level of loneliness.

The rate of loneliness described in our study is, however, considerably less than the 15 per cent prevalence of 'severe loneliness' reported by 
Scharf et al. (2002). This discrepancy could be explained by differences in the measures or populations: Scharf and colleagues used the De Jong Gierveld composite measure and the study was undertaken in deprived urban neighbourhoods. The level of widowhood was twice that of the national population, and it is most likely that the nature and location of their sample accounted for the substantially higher prevalence of loneliness. A similar effect may have influenced the findings of a survey that used the De Jong Gierveld scale in Perth, Western Australia (Iredell et al. 2003). It reported that 52 per cent were 'not lonely' and nine per cent were 'severely' or 'very severely lonely'. The highest reported rate of loneliness in a British study was 16 per cent in Hackney, inner London (Bowling, Farquhar and Browne I99I). The studies of inner city and deprived urban areas do therefore suggest that levels of loneliness among older people, however measured, are higher than in the general elderly population.

\section{Variations in the prevalence of loneliness by sub-groups}

The study has shown, as have many previous, that loneliness is not uniformly distributed through the older population. The univariate analysis identified strong relationships between loneliness and sociodemographic factors (being female, being widowed, living alone, being aged 75 or more years), health factors (the chronically physically/mentally ill, those with sensory impairments and poor health rating), material resources and a limited number of 'social' resources (time spent alone, changes in time alone/loneliness and availability of confiding relationships). These results confirm a well-established 'social epidemiology' of loneliness and are consistent with much previous research from Britain, Europe and North America. There was no statistical association with levels of social contact or proximity to children, friends and family. This could reflect the conceptual difference in the nature of our two measures. Our measure of loneliness is essentially 'subjective', whilst many 'objective' social-contact and proximity measures quantify geographical distance or the number and frequency of contacts. It has however been found that loneliness was linked to the availability of a confiding relationship, which suggests that the influential factor is not the number of relationships but their qualities.

Many of the instrumental factors are clearly inter-related. The multivariate statistical analysis indicated that two sets of factors were independently associated with loneliness, those that could be associated with vulnerability and those with protection. These novel results suggest that many of the factors previously thought to be associated with loneliness, such as gender, household status, and chronic illness/disability, are not 
independent in their influence. As De Jong Gierveld (2003) demonstrated, gender in itself is of limited utility when seeking to understand loneliness in later life, but needs to be interpreted in the light of other factors, such as living arrangements and partnership history, which influence the context of social engagement in later life. She also demonstrated the importance of differentiating, among those who live alone in old age, both between men and women, and between those for whom it is a new as opposed to a continuing or prior experience. As we gather more detailed data sets and develop more sophisticated methods of analysis, the complexity of social relationships in later life are revealed and more sophisticated models are required.

\section{Loneliness and social and health resources}

The multivariate models showed that vulnerability to loneliness was associated with two distinct sets of resources, social and health. Social resources were indicated by marital status, especially widowhood; 'time spent alone' and the perception of 'increased loneliness over the previous decade'. The link with widowhood is well established and supports the findings of Wenger et al. (I996). The other two 'social resource' factors equate with negative perceptions of the individual's social world and hence reinforce the subjective dimensions of loneliness. Two of the three health resources also refer to the ways in which older individuals evaluate their own later life; in this case concerning their health status; whilst the third relates to mental health. This evidence therefore suggests that vulnerability to loneliness is linked to two facets of the changing circumstances and expectations of later life. The vulnerability of the widowed to loneliness supports the proposition that it is a response to the specific change of circumstances (Witzelben i968; Weiss 1973), but individuals' expectations concerning their health and social relationships were also important. The possible association of loneliness with the failure of old age to live up to expectations requires further elucidation.

The second novel aspect of our analysis concerns the protective factors that were associated with a reduced vulnerability to loneliness. The new findings suggest that 'advanced age' and 'educational qualifications' were associated significantly and independently with a lower susceptibility to loneliness. The educational qualifications variable was marginally significant and should not be over-emphasised. The relationship with age was, however, robust and is intriguing. Other investigators' univariate (Fees, Martin and Poon 1999) and multivariate models (Wenger et al. 1996) have consistently suggested that increased age is a risk factor for loneliness. Our study has demonstrated the converse, once other factors such as 
widowhood are controlled. Those aged 85 or more years were at lowest risk of reporting loneliness, but given that the age group are less likely than younger elderly people to participate in research, this finding may be an artefact through non-response bias: only 77 of the 999 participants were in the age group.

There is, however, some support for our finding from Holmen and Furukara's (2002) survey in Sweden. They reported that amongst the participants aged 75 or more years at a io-year follow-up, rates of loneliness had fallen from 35.6 per cent (always/often/sometimes lonely) at baseline to 4.6 per cent at the follow-up. The age-relationship may arise through two sets of factors: a survivor effect, whereby the lonely exhibit elevated mortality/morbidity and have low survival in the community (either dying or being admitted to long-stay care); or an adaptive response, whereby those who do survive 'adapt' to the vicissitudes of old age such as bereavement or declining health. There will be complex interactions and linkages between changes in people's living circumstances and health in old age and the operation of both vulnerability and protective factors. Inevitably some people will experience increased loneliness and others a decrease (see Victor et al. 2004). Clearly this is an area for further research.

\section{Loneliness and the biography of later life}

Static, single point-in-time measurements and estimates have dominated studies of loneliness in later life, and few have adopted a longitudinal approach or examined the concept in a biographical or lifecourse framework (Holmen and Furukara 2002; Wenger and Burholt 2004). By inviting participants to compare loneliness now in the context of previous experiences, we have developed a four-fold typology of older people with or without loneliness: those who have never been lonely, those for whom loneliness is a new experience, those whose loneliness has decreased; and those who have always been lonely.

Both the univariate and multivariate analyses identified bereavement as a major risk factor for loneliness in later life, and it is plausible that the event and state is a major proximate cause or 'trigger'. A more precise hypothesis, that for a period after bereavement there is a heightened vulnerability to loneliness, may explain the observation that among those aged 85 or more years, the 'risk' of loneliness decreases. It may also help to explain the emergence of 'late onset' loneliness and, potentially, the factors that bear upon the 'decreasing' loneliness group.

Loneliness clearly compromises the quality of life of the older person and it is not a single, undifferentiated experience (Townsend and Tunstall I973). We have argued that there are different types of loneliness in later 
life characterised by distinct 'pathways' of onset. It can be speculated that the 'continuity' of loneliness into later life reflects the influence of personality factors and lifelong patterns of behaviour and inter-personal relationships (Fry and Debats 2002). 'Old age onset' loneliness may be a response to losses that can occur in later life such as bereavement or declining health (either one's own or a partner's) (Victor et al. 2002). The diversity of the experience of loneliness and its causes needs to be recognised in future research. The concepts of vulnerability and protective factors provide an appropriate conceptual framework with considerable potential for an increased understanding. There is also much need for a clearer understanding of the processes that reduce or buffer the impact of the identified risk factors, specifically if we are to develop effective and appropriate interventions to combat loneliness and social exclusion in later life.

\section{Acknowledgements}

We gratefully acknowledge the support of our funders, collaborators and the staff and interviewers of the Office of National Statistics (ONS) who conducted the fieldwork. The research was funded by the UK Economic and Social Research Council (award L480254042) as part of the Growing Older Programme. The Quality of Life Survey was part funded by grants held by Ann Bowling (ESRC grant L480254043) and Shah Ebrahim (Medical Research Council Health Services Research Collaboration). We are grateful to the ONS Omnibus Survey Unit for overseeing the fieldwork and preparing the data set. Those who carried out the original analysis and collection of the data hold no responsibility for their further analysis and interpretation. Material from the Omnibus Survey has been used with the permission of the Controller of The Stationery Office. The dataset will be held at the UK Data Archive at the University of Essex. Statistical advice was provided by Professor Janet Peacock and Louise Marston of Brunel University. Finally we thank all those older people who gave so freely of their time to participate in this study.

\section{NOTES}

I Those who agreed were re-interviewed two months after the initial contact. Further details of the design of the study and the data available are provided elsewhere (Bowling et al. 2002; Ayis et al. 2003; Victor et al. 2004).

2 Of those aged 85 or more years, I8 per cent rated themselves as 'often' or 'always' lonely. Similarly, 20 per cent of the widowed, and I7 per cent of those living alone, made the same rating.

3 Attrition and non-response in follow-up surveys of older people frequently exhibit non-response bias (Norton et al. 1994; Boersma et al. 1997; Hoeymans et al. 1998; Matthews et al. 2004). Older adults, members of ethnic minorities, people with cognitive or communication impairments and people with poor physical or mental health are often under-represented. 
4 On the basis of the evidence in the published literature, the over-representation of widowed people in the study sample may have inflated the estimates of the prevalence of loneliness. It should be considered that the comparator sources of data may also under represent similar categories of non-respondents.

\section{References}

Abolfotouh, M. A., Daffallah, A. A., Khan, M. Y., Khattab, M. S. and Abdulmoneim, I. 200r. Psychosocial assessment of geriatric subjects in Abha City, Saudi Arabia. Eastern Mediterranean Health Fournal, 7, 3, 48I-91.

Andersson, L. 1998. Loneliness research and interventions: a review of the literature. Ageing and Mental Health, 2, 4, 264-74.

Ayis, S., Gooberman-Hill, R. and Ebrahim, S. 2003. Long-standing and limiting illness in older people: associations with chronic diseases, psychosocial and environmental factors. Age and Ageing, 32, 3, 265-72.

Boersma, N., Feskens, E. J. M., Van den Bos, G. A. M. and Kromhout, D. 1997. Characteristics of non-responders and impact of non-response on prevalence estimates of dementia. International Fournal of Epidemiology, 26, I055-62.

Bond, J. and Carstairs, V. I982. The Elderly in Clackmannan. Scottish Health Services Studies 42, Scottish Home and Health Department, Edinburgh.

Bowling, A. I995. The most important things in life. International fournal of Health Sciences, 6 , $4, \mathrm{I} 6 \mathrm{o}-75$.

Bowling, A. 200I. Measuring Disease. Second edition, Open University Press, Buckingham.

Bowling, A., Farquhar, M. and Browne, P. I99I. Life satisfaction and associations with social networks and support variables in three samples of elderly people. International Journal of Geriatric Psychiatry, 6, 549-66.

Bowling, A., Banister, D., Sutton, S., Evans, O. and Windsor, J. 2002. A multidimensional model of the quality of life in older age. Aging and Mental Health, 6, 4, 355-71.

Brown, G. and Harris, T. 1978. The Social Origins of Depression. Tavistock, London.

Bury, M. and Holme, A. ig9i. Life After Ninety. Routledge, London.

Cornwell, J. I984. Hard Earned Lives. Tavistock, London.

De Jong Gierveld, J. I987. Developing and testing a model of loneliness. Fournal of Personal and Social Psychology, 53, I19-28.

De Jong Gierveld, J. I998. A review of loneliness: concepts and definitions, causes and consequences. Reviewes in Clinical Gerontology, 8, 73-80.

De Jong Gierveld, J. 2003. Social networks and social well-being of older men and women living alone. In Arber, S., Davidson, K. and Ginn, J. (eds), Gender and Ageing: Changing Roles and Relationships. Open University Press, Maidenhead, Berkshire, 95-1 Io.

Ellaway, A., Wood, S. and MacIntyre, S. i999. Someone to talk to? The role of loneliness as a factor in the frequency of GP consultations. British Fournal of General Practice, 49, $363-67$.

Fees, B., Martin, P. and Poon, L. I999. A model of loneliness in older adults. Fournal of Gerontology, Psychological Sciences, 54B, 4, 23I-9.

Fry, P. S. and Debats, D. L. 2002. Self-efficacy beliefs as predictors of loneliness and psychological distress in older adults. International Fournal of Aging and Human Development, 55, 3, 233-69.

Gibson, H. B. 200ı. Loneliness in Later Life. Macmillan, Basingstoke, Hampshire.

Hoeymans, F., Eefsting, J. A., Van den Brink, W. and Van Tilberg, W. I998. Non response bias in a study of cardiovascular diseases, functional status and self-rated health among elderly men. Age and Ageing, 27, I, 35-40. 
Holmen, K., Ericsson, K., Andersson, L. and Winblad, B. I992. Loneliness among elderly people in Stockholm: a population study. Fournal of Advanced Nursing, I 7, 43-51.

Holmen, K., Ericsson, K., Andersson, L. and Winblad, B. I994. Loneliness and living conditions of the oldest old. Scandinavian Fournal of Social Medicine, 22, 15-9.

Holmen, K. and Furukawa, H. 2002. Loneliness, health and social network among elderly people: a follow-up study. Archives of Gerontology and Geriatrics, 35, 3, 26I-7I.

Hunt, A. 1978. The Elderly at Home. Her Majesty's Stationery Office, London.

Iredell, H., Grenade, L., Boldy, D., Shaw, T., Howat, P. and Morrow, R. 2003. Coping with Loneliness and Social Isolation in Later Life: A Pilot Study. Freemasons' Centre for Research into Aged Care Services, Curtin University of Technology, Perth, Western Australia.

Jones, D., Victor, C. R. and Vetter, N. J. I982. The problems of loneliness in the community. Fournal of the Royal College of General Practitioners, 35, 136-9.

Matthews, F. E., Chatfield, M., Freeman, C., McCracken, C. and Brayne, C. 2004. Attrition and bias in the MRC cognitive function and ageing study: an epidemiological investigation. BiomedCentral Public Health, 4, I, I2. Available online at http://www. biomedcentral.com/I 47/ $-2458 / 4 /$ I2

Norton, M. C., Breitner, J. C. S., Welsh, K. A. and Wyse, B. W. I994. Characteristics of non-responders in a community survey of the elderly. Fournal of the American Geriatrics Society, 42, I252-6.

Prince, M. J., Harwood, R. H., Blizard, R. A., Thomas, A. and Mann, A. H. I997. Social support deficits, loneliness and life events as risk factors for depression in old age: the Gospel Oak project. Psychological Medicine, 27, 323-32.

Qureshi, H. and Walker, A. I989. The Caring Relationship: Elderly People and their Families. Macmillan, Basingstoke, Hampshire.

Rowe, J. W. and Kahn, R. L. I997. Successful aging. The Gerontologist, 37, 4, 433-40.

Russell, D. W. I996. UCLA loneliness scale (version 3): reliability, validity and factor structure. Fournal of Personality Assessment, 66, 20-40.

Scharf, T., Phillipson, C., Smith, A. E. and Kingston, P. 2002. Growing Older in Socially Deprived Areas: Social Exclusion in Later Life. Help the Aged, London.

Scharf, T. and Smith, A. E. 2004. Older people in urban neighbourhoods: addressing the risk of social exclusion in later life. In Phillipson, C., Allan, G. and Morgan, D. (eds), Social Networks and Social Exclusion. Ashgate, Aldershot, Hampshire, I62-79.

Schwartz, G. E. and Sprangers, M. A. G. 2000. Adaptation to Changing Health: Response Shift in Quality of Life Research. American Psychological Association, Washington DC.

Seabrook, J. I973. Loneliness. Maurice Temple Smith, London.

Shanas, E., Townsend, P., Wedderburn, D., Henning, F., Milhof, P. and Stehouwer, J. (eds) I968. Old People in Three Industrial Societies. Routledge and Kegan Paul, London.

Sheldon, J. H. 1948. The Social Medicine of Old Age. Oxford University Press, Oxford.

Tijhuis, M. A., de Jong Gierveld, J., Festiens, E. J. and Kromhout, D. I999. Changes in and factors related to loneliness in men: the Lutphen elderly study. Age and Ageing, 28, 5, $49^{\mathrm{I}}-5$.

Townsend, P. 1957. The Family Life of Old People. Routledge and Kegan Paul, London.

Townsend, P. I968. Isolation and loneliness. In Shanas, E., Townsend, P., Wedderburn, D., Friis, H., Milhoj, P. and Stehouwer, J. (eds), Old People in Three Industrial Societies. Routledge and Kegan Paul, London, 258-87.

Townsend, P. and Tunstall, J. I973. Sociological explanations of the lonely. In Townsend, P. (ed.), The Social Minority. Allen Lane, London, 257-63.

Tunstall, J. ig66. Old and Alone. Routledge and Kegan Paul, London.

Victor, C. R., Scambler, S., Bond, J. and Bowling, A. 200o. Being alone in later life: loneliness, isolation and living alone in later life. Reviews in Clinical Gerontology, 10, 407-17.

Victor, C. R., Scambler, S., Bond, J. and Bowling, A. 200I. Loneliness in later life: preliminary findings from the Growing Older project. Quality in Ageing, 3, I, 34-4I. 
Victor, C. R., Scambler, S., Shah, S., Cook, D. G., Harris, T., Rink, E. and de Wilde, S. 2002. Has loneliness amongst older people increased? An investigation into variations between cohorts. Ageing \& Society, 22, I, I-I3.

Victor, C. R., Scambler, S. J., Bond, J. and Bowling, A. 2004. Loneliness in later life. In Walker, A. and Hennesey, C. (eds), Quality of Life in Old Age. Open University Press, Maidenhead, Berkshire, I07-26.

Walker, A. and Maltby, T. 1997. Ageing Europe. Open University Press, Buckingham.

Walker, A., O'Brien, M., Traynor, J., Fox, K., Goddard, E. and Foster, K. 2002. Living in Britain: Results of the 200I General Household Survey. Supplementary Report People Aged 65 Years and Over. Stationery Office, London. Available from http://www.statistics.gov.uk/ lib20or/section 373o.html

Weeks, D. J. 1994. Review of loneliness concepts, with particular reference to old age. International Fournal of Geriatric Psychiatry, 9, 345-55.

Weiss, R. S. 1973. Loneliness: The Experience of Emotional and Social Isolation. MIT Press, Cambridge, Massachusetts.

Wenger, G. C. 1983. Loneliness: a problem of measurement. In Jerrome, D. (ed.), Ageing in Modern Society. Croom Helm, Beckenham, Kent, I45-67.

Wenger, G. C., Davies, R., Shahtahmesebi, S. and Scott, A. 1996. Social isolation and loneliness in old age: review and model refinement. Ageing \& Society, I6, 333-58.

Wenger, G. C. and Burholt, V. 2004. Changes in levels of social isolation and loneliness among older people in rural Wales: a 20 year longitudinal study. Canadian fournal on Aging, 23, 2, II5-27.

Witzelben, H. D. I968. On loneliness. Psychiatry, 21, $3^{\mathrm{I}-43 .}$

Accepted I2 November 2004

Address for correspondence:

Christina Victor, School of Health and Social Care, University of Reading, Bulmershe Court, Reading, RG6 IHY, UK.

e-mail: c.r.victor@reading.ac.uk 